\title{
VISUALIZATION AND TEACHER EDUCATION: SOME TRENDS IN CHEMICAL EDUCATION
}

\author{
Luanna Gomes de Gouvêa, \\ Valéria Campos dos Santos, Agnaldo Arroio \\ Faculty of Education, University of Sao Paulo, Sao Paulo, \\ Brazil
}

\begin{abstract}
The current scenario of teaching chemistry has introduced the visual tools as a way to solve the cognitive demand of students and teachers. These tools contribute to facilitate the teaching of various chemistry topics, making visible the microscopic interactions. Despite the wide variety and functionality of the visual tools, teachers have been faced with the unknown, since they are not prepared to use these tools in the classroom. Motivated by this fact, research on pre-service and in-service teacher educational programs has shown paths and initiatives aiming to assist and prepare the teacher to use the visual tools. This study presents a reflexive approach of some researches about the use of visualizations and teacher training programs (in-service and pre-service). Based on the trends presents in selected papers, it was concluded that researchers raised the ideas of teachers about the uses of these tools. This can base initiatives to work with these conceptions, solving doubts, questions and fears of using the computer. The teachers show interest in use these tools in their classes showing the importance and the current necessity of courses that enable the teacher to use visualization tools. Although there are some proposals for teacher training programs, there is much more to study and research in this area.
\end{abstract}

Key words: chemical education, teacher education, visualization.

\section{Introduction}

The great development of hardware that allows us to use powerful computers that support the design of several visualizations with scientific models, especially dynamic models, simulations and interactive modeling software that can be displayed and manipulated in a virtual format and by remote access.

The accelerated development of Information and Communication Technologies in Natural Science Education followed by several studies in the cognitive theory area, have promoted the construction of many visual tools (animations, simulations, games, statics or dynamics virtual 2D and 3D images, multimedia software's, etc.) that have been placed to the disposition of educators (Arroio, 2012).

Teaching chemistry requires tools that assist teachers and students in the educational process, since the chemistry requires visualization of interactions that occur at the submicroscopic level, which are difficult to understand. According to Touli, Radid and Talbi (2011), when chemical concepts are misunderstood or misinterpreted by students, it opens a space for inadequate conceptions which may accompany the student through basic education and stay in even higher level of education. Van Berkel, Pilot and Bulte (2009) 
point out that these are also inadequate conceptions belonging to teachers, who can not have well established concepts, often because the abstractions required for understanding the chemical processes. To overcome this barrier, students and teachers create ways to accept the invisible using only definitions and explanations macroscopic and probably no real meaning (Van Berkel, Pilot and Bulte, 2009).

To improve this situation, visual tools (pictures, simulations, animations, software, etc.) have been developed to assist in the education process of chemistry, enabling the visualization of atoms and molecules in order to meet the cognitive needs of students. Treagust and Chandrasegaran (2009) showed that students who attend classes with uses of visualization tools have a better and deeper understanding of chemical concepts compared to students who attended to traditional teaching tools. Currently, there are several visual tools that have been developed with the technological advance enabling tools that address different subjects in a contextualized form.

With technological development, projects aimed at the integration of computers in schools are becoming increasingly evident. But it cannot just insert computational tools in schools; it should also train the teachers to know how to use these technologies in a way that makes them educational tools. The computer programs for teaching chemistry do not work by itself as an educational tool; it depends on the interactions that occur in the classroom and their adjustment to the curriculum (Carrarer, 1992). So, it is necessary to prepare teachers with skills that make them able to use visual tools in order to assist students.

In the research ACOT (Apple Classrooms of Tomorrow), resulting from collaboration between Apple Computer and several schools, a survey was conducted from 1986 to 1989 in order to identify what happens when teachers and students gain access to technologies. In the research, Dwyer, Ringstaff and Sandholtz (1990) presented five stages (Entry, Adoption, Adaption, Appropriation and Invention) crossed by teachers while adapting to technologies. These stages were updated by Bilek, Machkova and Simonova (2011), as follows:

1. Non-user classroom - teacher may have personal ICT (Information and communications technology) skills but has not taught with ICT;

2. Adopter Programme - ICT teacher uses the materials it comes When It fits in with the teaching;

3. Adapter style - teacher modifies materials to suit different pupil groups and existing teaching;

4. Appropriator - Develops teacher and uses the ICT tools in a different context or topic novel mode of use (implying a shift of pedagogy);

5. Creator - teacher creates new materials and / or fosters ICT use in colleagues (Bilek, Machkova, Simonova, 2011 p. 397).

To cross one stage to another is necessary that the teacher has passed by training processes. Each phase has its importance and be inserted in each one, one at a time, may help the teacher to build the knowledge, making him more active and safe in their classes.

Given the above, the aim of this paper is to address the use of visualization and in teacher training programs, showing trends in research in this area. This reflection is important since the knowledge about the theme visualization and about the pre-service and in-service teacher educational program, enables us to perceive what is being done in re- 
searches about teacher training programs to use visual tools and recognize the importance of these studies.

\section{Methodology of Research}

In this work, a search for articles was done. The objective was select papers that discuss visualizations and teacher training programs in teaching chemistry. The search was made in the ERIC (Educational Resources Information Center), Science Direct and Google Scholar databases, using the keywords: visualization, teacher training program, in-service teachers, pre-service teacher and chemistry teaching. The articles were chosen by presenting relevant results at the area of teacher training in the field of visualizations for chemistry teaching

Based on Taylor (2010), the articles were read for completely and critical analyzed, focusing on determine the current trends and what paths the researchers opened in the creation of initiatives to train teachers in use of visualizations in their classes. The articles were organized according with their research focus, showing data and findings, presenting a summary of their collaborations for the research in chemical education. Finally, the areas that need more research was analyzed, showing possible further works who aimed teacher training programs.

\section{Results of Research}

The articles on the use of visualizations and teacher training have shown researches are being conducted with focus in training in-service teacher as well in training preservice teachers, as show in table 1. In addition, selected articles show that the goals of the researches can be divided into two categories:

1. Survey of teacher's conceptions about the use of visualizations;

2. Evaluation and / or implementation of training activities regarding the use of visualizations.

Four articles were considered as belonging to the first category. Among them two were referring just pre-service teacher training, one about in-service teacher training and one about training of in-service and pre-service teachers. In the second category, there were three articles. Two of them showing in-service teacher educational programs and one show the pre-service teachers educational programs (Table 1).

As shown in Table 1, in the present study were found only seven articles showing the use of visualizations in teacher training program. This shows that there is still much to be researched in the area. Future research should embrace both pre-service training as teacher of in-service teacher training to remedy the problems of training currently existing. 
Table 1. Focus of articles presented in this research.

\begin{tabular}{|c|c|c|c|}
\hline Authors (year) & $\begin{array}{l}\text { In-service } \\
\text { teacher }\end{array}$ & $\begin{array}{l}\text { Pre-service } \\
\text { teacher }\end{array}$ & Aims \\
\hline Ferreira and Arroio (2009) & & $\mathrm{X}$ & \multirow{4}{*}{$\begin{array}{l}\text { Identifying teachers' con- } \\
\text { ceptions about the use of } \\
\text { visualizations }\end{array}$} \\
\hline $\begin{array}{l}\text { Savec, Vrtacnik and Peklaj } \\
(2006)\end{array}$ & $\mathrm{X}$ & $\mathrm{X}$ & \\
\hline Aksela and Lundell (2008) & $\mathrm{X}$ & & \\
\hline $\begin{array}{l}\text { Bilek, Machkova and } \\
\text { Simonova (2011) }\end{array}$ & & $\mathrm{X}$ & \\
\hline $\begin{array}{c}\text { Weerawardhana, Ferry and } \\
\text { Brown (2006) }\end{array}$ & & $\mathrm{X}$ & \multirow{3}{*}{$\begin{array}{l}\text { Evaluate and / or imple- } \\
\text { ment proposals for teach- } \\
\text { er training programs for } \\
\text { using visualizations }\end{array}$} \\
\hline Gabini and Diniz (2009) & $\mathrm{X}$ & & \\
\hline Dori and Barnea (1997) & $\mathrm{X}$ & & \\
\hline
\end{tabular}

\section{Discussion of Results}

The investment in research about in-service teachers training can be due to lack of adequate training for pre-service teachers. Training courses for teachers are not preparing future teachers for the use of visual tolls adequately or, as often happens, the teachers do not even know the existence of these tools due to problems in the initial training.

Some of the articles selected on the use of visualizations have shown the vision of teachers in training on visual tools, raising the needs they present. Among these studies, there are the articles: Ferreira and Arroio (2009); Savec, Vrtacnik and Peklaj (2006); Aksela and Lundell (2008); and Bilek, Machkova and Simonova (2011) which present a summary of responses to questionnaires designed to investigate the use and conceptions of teachers in training on the use of visual tools.

Ferreira and Arroio (2009) administered questionnaires to pre-service teachers, who attended the course Methodology of Teaching Chemistry at University of São Paulo - Brazil. Among the 24 students who answered the questionnaire, 16 had some practice as a teacher, the others had not. From the responses of pre-service teachers, Ferreira and Arroio (2009) observed that the most used visual tools by the student teachers who had taught are the images and the models because they are easier to use due to access or comfort. This statement of the authors shows that teachers still have some anxiety on using computational tools for having the idea that these are difficult to use. The authors note that the figures and models are most used where abstractions are required. It may be noted that teachers use visual tools in most cases where the content is more complex, but these tools could be used at other times as a different way to approach the content, motivating the students. The authors also found that pre-service teachers have the conception that the representations are copies and not the real attempts to show something invisible:

Considering also the specifics of these tools, it fears that in the initial training courses, these teachers often are not fitted properly the notion that these molecular objects are representations of the molecular entity and imagery can be defined as an analogy of what happens in the plane assume submicroscopic matter and not a picture of reality. (Ferreira and Arroio, 2009, p. 35). 
The conception of the teachers of recognize the tools as a reproduction of the real must be worked out in detail in the training courses, showing that the visuals are alternatives that scientists have found, after much work, to represent and explain an invisible world. Finally, the authors highlight that, according to the questionnaire responses, the student teachers feel unprepared for the use of visual tools, as these topics are covered superficially in the undergraduate course. The research of Ferreira and Arroio (2009) shows how that teachers in pre-service have little knowledge about the variety of visual tools and their applications in teaching chemistry.

Another research that deals with the survey of visualization and opinions of teachers is Savec, Vrtacnik and Peklaj (2006), which analyzed responses from questionnaires administered to pre-service teachers and in-service teachers in continuing education regarding the use of models in teaching chemistry. The survey was conducted with 54 chemistry teachers from different regions of Slovenia and 21 teachers in training at the University of Ljubljana and University of Maribor. The authors found that in both groups of teachers believe that it is important to use models in teaching chemistry, but especially in the teaching of organic molecules. As in the work of Ferreira and Arroio (2009), Savec, Vrtacnik and Peklaj (2006) contacted teachers use visual tools to more complex concepts of chemistry.

The results obtained by the researchers showed that the majority of teachers said they would use molecular models often if the school conditions were more favorable (Savec, Vrtacnik and Peklaj, 2006). A possible reason is the lack of government support for the acquisition of teaching materials. Perhaps, it is noteworthy that the molecular models can be built with alternative materials providing the same function as industrial models.

Savec, Vrtacnik and Peklaj (2006) also shows that, besides the scarcity of molecular models in schools, most teachers do not know how to use computer programs to build molecular structures. According to the authors, teachers are aware of the importance of learning to use computational tools and have an interest in improving their knowledge. Based on the research the authors present some initiatives that can be used to improve this situation:

1. The financer - the Ministry of Education, Science and Sport - should be informed about the situation and encouraged to allocate funds for the improvement of schools` instructional infrastructure;

2. The existing curriculum for the tertiary education of prospective teachers should be improved by giving more emphasis to topics regarding models of molecules and crystals (introducing contemporary technologies, discussing possible misconceptions, and indicating more practical examples of their use);

3. Special training courses for in-service chemistry teachers, aimed at improving their scientific computer literacy and indicating practical examples of how models can be used in the educational process, should be developed;

4. Educational materials focusing on molecular and crystal models, equipped with methodological suggestions for their use, should be developed to support the educational process. The materials should be preferably in electronic format (e.g. web-based or CD-ROM) to enable direct access to pseudo-3D models; 
5. Possibilities for further cross-curriculum linkages between chemistry and other subjects at the secondary level to stimulate the development of students`spatial intelligence (e.g. in mathematics by using different molecular structure representations as objects when teaching geometry; in biology by using models when teaching genetics, etc.) should be examined and implemented. (Savec, Vrtacnik and Peklaj, 2006.p. 390)

Aksela and Lundell (2008) were also based on the application of questionnaires to teachers in continuing education, working in schools in Finland that attended modeling courses. The objectives were to identify the reasons for the use of modeling or not, how they are used and the resources required for the use in the classroom. The authors observed that teachers have found several benefits of using modeling from observation of their own practice. The main reason for using this tool was raised as access to visualization, illustrating difficult concepts of understanding. According to the authors most teachers use modeling to show 3D molecules in teaching isomerism, chemical bonding and molecular orbitals. As in the previously cited works, teachers use visual tools in explaining complex concepts.

According to Aksela and Lundell (2008), some teachers had never used visual tools in their classes due to lack of software or opportunities to use computers in schools. However there is currently a wide variety of free software for teaching chemistry. What may have occurred is the lack of knowledge about the existence of free tools by the teacher. It is also worth mentioning that there are visual tools that do not require the use of computers. Also, models can be built with alternative materials (Styrofoam ball, cover refrigerate, toothpicks, plastic straws, etc.).

The main uses of modeling tools were in homework or classroom works. The authors highlight that must be included initiatives that propose training to teachers, aiming the knowledge on how create and use different approaches using visual tools. In relation to the resources needed to use the modeling, the teachers made it clear they needed more preparation to use the tools, noting that, even with easy to use software, they had difficulties to make them become educational tools.

The research presented in Bilek, Machkova and Simonova (2011) was applied to pre-service chemistry teachers of the Czech Republic, aiming to remedy the problem that they had to create, implement and evaluate activities that include computational simulations and animations. The data collection was made from observation and questionnaires to raise difficulties in the use of visual tools. As a result, the authors report that teachers in training know the visual tools and can propose activities making use of these tools. These teachers prefer using animations and simulations in the explanatory part of the lesson. Little space is given to apply these tools into exercises or as introduction of concepts.

Bilek, Machkova and Simonova (2011) show that most teachers in training agree that the visual tools can never replace the experimental classes in science teaching. According to the authors the visual tools should explain microscopically the interactions occurring in the experiments or should be used when the experiment is impossible to be held in the school environment by shortages of materials, being dangerous or any other problem. The authors also emphasize the need for further research pedagogical and psychological that the advance in the technology demands. 
From the research cited above is possible to note the pros and cons that student teachers encounter when faced with visual tools. These researches can provide base for the creation of new initiatives aiming to train teachers. Training activities can be developed based on previous conceptions of teachers as those raised in the polls above.

Some articles selected in this paper present the results of training initiatives (workshops and training courses). The researches of Weerawardhana, Ferry and Brown (2006), Gabini and Diniz (2009) and Dori and Barnea (1997), show that student teachers are being exposed to activities that aimed to create kits, instructional sequences, schedules and mini-courses.

The research of Weerawardhana, Ferry and Brown (2006) was conducted with eight teachers in training, who participated in two workshops that targeted the use of visual tools in teaching chemistry. In the first workshop was conducted a review of the concepts of chemical equilibrium, using the CHEM software and VisChem. In the second workshop, teachers in training split up into three groups and were encouraged to reorganize the interface of this software in order to place them, along with other tools in sequences education that would be applied by them in two public schools. The article's authors used interviews and observations of lessons to assess the importance of these sequences in chemistry teaching and the professional development of teachers in training.

As results, the authors found that pre-service teachers used a variety of visual tools methodologies and the three representational levels (macroscopic, microscopic and symbolic) in their approaches. Also, it was possible that teachers adapt the various visual tools existing to meet the needs of teaching chemistry. The authors highlighted the fact that the sequences are made in groups favoring the sharing of ideas and experiences, favoring professional development and showing the effectiveness of workshops to train teachers with specific bases to teach chemistry (Weerawardhana, Ferry and Brown, 2006).

Gabini and Diniz (2009) show a workshop for teachers of 36 high schools in continuing education, during the course attended averaged 30 teachers. The workshop involved the use of free software, software available in the market and on websites for teaching chemistry. Besides the use of softwares teachers in continuing education had to propose a plan using these softwares. Teachers also have access to a virtual environment where they could discuss articles, textbooks, softwares and exchange experiences during the development of the workshop. The authors used the discussion forums, reviews, reports and records researcher to evaluate the workshop.

According to Gabini and Diniz (2009), the workshop was not intended to give teachers a methodology of how to use the visuals tools in the classroom. Instead, its role was to encourage self review and evaluation of their teaching practice analyzing whether the action really brings contribution for what is being taught. According to the authors, the exercise of analyses software and create activities with the use of visual tools favored the development of a critical view of the teachers. The discussions made in the virtual environment give the teachers the opportunity to review and rework their proposals according to the exchanges of experiences that occurred during the workshop.

Dori and Barnea (1997) developed a module for teaching polymers and used it to investigate the effect of a training course on the attitudes of teachers in service as to the uses of computers in the classroom. The study was constituted by two teacher groups: an experimental group and a control group. The experimental group was composed of 39 
teachers. The control group was composed of 27 teachers who participated of a training program.

Teachers participating in the research of Dori and Barnea (1997) were challenged to use a program module on polymers to develop your own mini-course. This task given to teachers aimed to help eliminate the fear of computer use by promoting the introduction of different technologies. The results obtained by the authors showed that teachers who had attended the training showed greater safety when using the polymers module including by reporting the use of these in their classes since the beginning of the course participation. Initially, the teachers in the experimental group saw no advantages in using the polymers module. After the training they realized that the tool can improve understanding of the student. The authors highlight the difference of performance between the groups showing that the control group had a higher utilization and that the experience is a very important factor for better use of visual tools.

The above research led the understanding that the teacher training program brings satisfactory results in training teachers to use visualizations. However, much more still needs to be studied due to the constant technological progress which is directly reflected in the school, requiring continuous training teachers. Given the analysis of the research presented here can infer some aspects that should be present in training courses for teachers. These are shown below:

- Assist teacher to lose the fear of using the computer in the classroom;

- Assist teacher to recognize the existing visual tools;

- Assist teacher to understand that visual tools are not copies of real;

- Assist teacher to learn how to create activities that include visual tools validly and bring meaning to students;

- Encourage self-critical to teacher that he grants to create and recreate their sequences of classes and select tools that best meet their goals in the classroom;

- Train teachers to let them know to use the available software for the teaching of chemistry;

- Encourage the use of visual tools in other content besides the considered complex and difficult understanding as technology facilitator of knowledge construction;

- Encourage the practice and experience exchange among teachers on the use of visual tools that can build more knowledge within that aspect;

- Encourage critical view of teacher training so that they can select visual tools that do not show conceptual errors that may confuse students.

- Teach teachers to seek the web free tools on the web

- Show that in schools where resources are scarce, alternative materials can be used to build models, it is just needed the simply stimulus of the creativity of teacher.

\section{Conclusions}

In this study, some researches that address visualizations and teacher training was grouped. The articles read address different research topics, but all of them focus on assisting the teacher in the exercise of its function as an educator. 
The studies show that teachers have an interest in participating in activities, courses, lectures and workshops, which can assist them to use visual tools. They show that different methodologies are being studied to teach teachers to use and create activities which use visualizations in their approaches. In addition, they show the importance of teacher reflection on their own teaching practice. To accomplish that, himself has to evaluate its performance benefits and the performance of the methodology applied in order to improve it.

There is still a need for initial training and continuing courses for chemistry teachers. These courses should help them in the use of visual tool, since the technologies reflects on the students the need for new approaches to them to solve the doubts and make them reflect and understand the chemistry at all levels providing concrete and coherent learning. It is needed more investigations on the effectiveness of training for undergraduate chemistry students, or teachers in initial training, on the use of visual tools at chemistry classes.

Also, there is a need of works trying to identify deficiencies of the initial preparation of teacher at the University and the relation of these deficiencies with the difficulties that these teachers present in service. From in-service teachers, it was possible note they need to know the applications of visual tools, because they do not know how to use them even knowing its importance to the teaching of chemistry. In addition, in-service teacher must attend training courses that assist in creating activities that use visualizations so it does not become meaningless to the student. For the in-service teachers that have not participated in training that aims at the use of visual tools, continuing education should be studied in order to solve the problems of initial training. For the pre-service teachers the initial formation should be improved, addressing several teaching tools.

\section{Acknowledgements}

Acknowledge the scholarship from CAPES, Brazil.

\section{References}

Arroio, A. Visualizations in Natural Science Education: What we can "see"? Journal Baltic Science Education, 11 (2), 2012.

Aksela, M., \& Lundell, J. (2008). Computer-based molecular modelling: Finnish school teachers' experiences and views. Chemistry Education Research and Practice, 9, 301-308.

Bilek, M., Machkova, V., \& Simonova, I. (2011). The Virtual World in the General Chemistry Education - Experience in Developing the Pregraduate Teachers' Competences in the Czech Republic. Information Society (i-Society) International Conference, pp. 393397.

Carrarer, D. (1992). O papel do computador na aprendizagem. Acesso, 5, 21-30.

Dori, Y. \& Barnea, N. (1997). In-servisce chemistry teachers' training: the impact of introducing teachers' attitudes and classroom implementation. International Journal of Science, 5, 577-592.

Dwyer, D., Ringstaff, C., \& Sandholtz, J. (1990). Teacher Beliefs and Practices Part I: Patterns of Change The Evolution of Teachers' Instructional Beliefs and Practices in 
High-Access-to-Technology Classrooms: First-Fourth Year Findings. Cupertino: Apple Computer Inc.

Ferreira, C. R., \& Arroio, A. (2009). O Uso de Visualizações no Ensino de Química: a formação inicial do professor de química. Revista Brasileira de Ensino de Química, $2,31-42$.

Gabini, W. S., \& Diniz, R. E. (2009). Formação Continuada de professores de química: Um proposta envolvendo a inserção da informática nas aulas práticas de química. Revista Brasileira de Pesquisa em Educação em Ciências, 9, 1-17.

Savec, V. F., Vrtačnik, M., J. K., \& Peklaj, C. (2006). In-Service and Pre-Service Teachers` Optionion on the Use of Models in Teaching Chemistry. Pedagogical Paper, 53, 381-390.

Taylor, D. (2010). The literature review: A few tips on conducting it. Canadá: Toronto University: http: / / www.writing.utoronto.ca / advice / specific-types-of-writing / literature-review.html. Retrieved December, 2, 2012

Touli, E. H., Radid, M., \& Talbi, M. (2011). Teacher-training: Analyses of teacher's representations about their impact on teaching of chemical reaction under the current system. Procedia Social and Behavioral Sciences, 15, 2122-2131.

Treagust, D. F., \& Chandrassegaran, A. L. (2009). Instructional Programmer Designed to Enhance Secondary Student's Competence. In: J. K. Gilbert, D. Treagust, J. K. Gilbert, \& D. Treagust (Eds.), Models and Modeling in Science Education: Multiple Representations in Chemical Education (Vol. 4, pp. 151-168). Springer.

Van Berkel, B., Pilot, A., \& Bulte, A. M. (2009). Micro-Macro Thinking in Chemical Education: Ehy and How to Escape. In: J. K. Gilbert, D. Treagust, J. K. Gilbert, \& D. Treagust (Eds.), Models and Modeling in Science Education: Multiple Representations in Chemical Education (pp. 31-54). Springer.

Weerawardhana, A., Ferry, B., \& Brown, C. (2006). Use of visualisation software to support understanding of chemical equilibrium: The importance of appropriate teaching strategies . Proceedings of the 23rd annual ascilite conference: Who's learning? Whose technology? pp. 853-861.

Received 14 December 2012; accepted 15 February 2013

\section{Luanna Gomes de Gouvea}

Master Student in Science Education, Faculty of Education, University of São Paulo, São Paulo, Brazil E-mail: luanna.gouvea@yahoo.com.br

Website: http: // www.usp.br

\section{$\square$
Valeria Campos dos Santos}

$\mathrm{PhD}$. Student in Science Education, Faculty of Education, University of São Paulo, São Paulo, Brazil

E-mail: valcampos07@hotmail.com

Website: http: / / www.usp.br

Agnaldo Arroio
PhD, Associate Professor, University of Sao Paulo,
Faculty of Education, Av. da Universidade 308, blo-
co A, sala 109., Butantã, 05508-040 São Paulo - SP
- Brazil
E-mail: agnaldoarroio@yahoo.com
Website: http: / / usp-br.academia.edu / AgnaldoAr-
roio

